\title{
MAGNETIC RESONANCE IMAGING OF SYSTEMIC VENOUS ANOMALIES
}

\author{
James H. Ellis, ${ }^{1.2 *}$ Janette S. Denham, ${ }^{1}$ John R. Bies, ${ }^{1} \dagger$ \\ Eldon W. OLSON' $\ddagger$ and David A. CORY' \\ 'Department of Radiology, Regenstrief Institute and Indiana University Medical Center. Indianapolis, IN 46223 \\ and 'Department of Radiology, University of Michigan Medical Center, Ann Arbor, MI 48109, U.S.A.
}

(Received 27 June 1985; received for publication 20 November 1985)

\begin{abstract}
Seven cases of anomalous development of the systemic great veins were found in the first 18 months of adult body imaging with a $0.15 \mathrm{~T}$ resistive magnetic resonance unit. Comparison was made with CT. In most cases, CT and MRI were equivalent in demonstrating the abnormality. In one case, MRI was superior to a drip-infusion CT. MRI was less successful when the low signal abnormal vein was adjacent to normal structures of low signal. Awareness of the MRI appearance of venous anomalies will aid their recognition as incidental findings.
\end{abstract}

Veins, magnetic resonance imaging Veins, computed tomography Venous anomalies

\section{INTRODUCTION}

Anomalies of the systemic venous system are well described in the radiological literature. For example, persistent left superior vena cava (SVC) has an incidence of $0.3 \%$ in the normal population, compared to $4.4 \%$ of the 275 patients with suspected congenital or acquired heart lesions studied by Cha [1]. Various inferior vena caval and renal vein anomalies have been documented both by autopsy and CT. The relative frequencies of these conditions in several studies are given in Table 1.

\begin{tabular}{|c|c|c|c|c|c|c|c|c|}
\hline $\begin{array}{l}\text { Type of series } \\
\text { Author } \\
\text { Size of study }\end{array}$ & $\begin{array}{l}\text { Autopsy } \\
\text { Seib [2] }\end{array}$ & $\begin{array}{c}\text { Autopsy } \\
\text { Adachi [3] } \\
1055\end{array}$ & $\begin{array}{c}\text { Autopsy } \\
\text { Reis [4] } \\
500\end{array}$ & $\begin{array}{c}\text { Autopsy } \\
\text { Davis [5] } \\
270\end{array}$ & $\begin{array}{c}\text { CT } \\
\text { Alexander [6] } \\
1200\end{array}$ & $\begin{array}{c}\text { CT } \\
\text { Ueda [7] } \\
874\end{array}$ & $\underset{1260}{\text { CTeda }}$ & $\begin{array}{c}\text { CT } \\
\text { Mayo [8] } \\
1140\end{array}$ \\
\hline Anomaly & \multicolumn{8}{|c|}{ Frequency $(\%)$} \\
\hline Duplication IVC & 3.0 & 1.51 & 2.20 & & 0.08 & 1.03 & & 0.44 \\
\hline Transposition IVC & 0.5 & 0.28 & 0.20 & & 0.08 & 0.69 & & 0.35 \\
\hline Retroaortic LRV & & & & 1.8 & 0.08 & & & \\
\hline Circumaortic LRV & & & 6.0 & 1.5 & 0.25 & & & 0.09 \\
\hline Retrocaval Ureter & & & & & & & & 0.09 \\
\hline Azygos Continuation & & $0^{*}$ & & & & & 0.08 & \\
\hline
\end{tabular}

*Looked for, but not found.

IVC--inferior vena cava: LRV-left renal vein.

Despite their low incidence, the identification of these anomalies is important. Presurgical definition of vascular anatomy can help to prevent serious intraoperative hemorrhage [9]. Knowledge of a duplicated inferior vena cava (IVC) is helpful during adrenal venography and renal vein sampling [10] and could prevent unsuccessful placement of caval filters. Left SVC can complicate cardiac catheterization [1] or, if there is anomalous drainage to the left atrium, can be the source of an unsuspected shunt [11].

\section{MATERIALS AND METHODS}

The reports of all patients who were evaluated with both thoracic or abdominal magnetic resonance (MR) imaging and computed tomography (CT) were reviewed for incidental findings of congenital

\footnotetext{
* Please address requests for reprints and correspondence to: James H. Ellis, M.D., Radiology Service (114). Veterans Administration Medical Center, 2215 Fuller Road, Ann Arbor, MI 48105, U.S.A.

† Present address: Department of Radiology, St. Mary`s Medical Center, Evansville, IN 47715, U.S.A.

$\ddagger$ Present address: Department of Radiology, St. Joseph’s Hospital, Lexington, Kentucky, U.S.A.
} 
anomalous systemic veins. Approximately 241 cases over 18 months were analyzed. Two radiologists reviewed the cases for a consensus opinion of the information yielded by both $\mathrm{CT}$ and MR. Images were evaluated for clarity of depiction of the abnormalities, particularly contrast discrimination from surrounding structures and visualization of the appropriate venous anastomoses. Emphasis was placed on the inherent imaging properties of the anomalous veins, i.e. flow void phenomenon or paradoxic enhancement [12] for MR and contrast enhancement for CT. As far as possible, spatial resolution was ignored.

The CT scans were obtained on third or fourth gencration scanners. Intravenous drip infusion of contrast was routinely administered. A bolus contrast injection was selectively given to clarify any questionable abnormalities.

The MR images were obtained on an investigative $0.15 \mathrm{~T}$ resistive magnet manufactured by Technicare Corporation. Proton resonance frequency was $6.25 \mathrm{MHz}$. Spin echo (SE) and inversion SE images were available. For SE images, repetition times (TR) ranged from 250 to $1000 \mathrm{msec}$ while echo times (TE) were 24,30 or $60 \mathrm{msec}$. Inversion SE images were performed with an inversion time (TI) of $400 \mathrm{msec}$, TE of $30 \mathrm{msec}$ and TR of $1400 \mathrm{msec}$. Slice thickness was $15 \mathrm{~mm}$. All patients gave informed consent in a manner approved by the local review board on the protection of human subjects.

\section{RESULTS}

Six patients had congenital anomalies of abdominal veins and one had a thoracic anomaly (Table 2). Two cases of circumaortic left renal vein (LRV) were equally well seen on CT and MR images (Fig. 1). The two methods also were equal in demonstrating two cases of retroaortic left renal vein. The third retroaortic LRV initially was falsely interpreted by CT to represent adenopathy. MR clarified the vascular nature of the lesion. A repeat $\mathrm{CT}$ exam with bolus injection of contrast produced images equivalent to MR (Fig. 2). CT was superior to MR in delineating a duplicated IVC (Fig. 3) and a duplicated SVC (Fig. 4).

Table 2. Seven patients with anomalous systemic veins

\begin{tabular}{ccccc}
\hline Case & \multicolumn{1}{c}{ Clinical Presentation } & \multicolumn{1}{c}{ Anomaly } & MR vs CT & Correlation \\
\hline 1 & 40 y male with testicular cancer & Circumaortic LRV & Equal & Surgical \\
2 & 33 y male with testicular mass & Circumaortic LRV & Equal & Angiographic \\
$3^{*}$ & 67 y female with lymphoma & Retroaortic LRV & Equal & MR better than infusion CT \\
4 & 56 y female with ovarian cancer & Retroaortic LRV & MR equal to bolus CT \\
5 & 67 y female with cervical cancer & Retroaurtic LRV & Equal & CT belter \\
6 & 46 y male with testicular cancer & Duplicated IVC & CT better \\
7 & 58 y male with testicular cancer & Duplicated SVC & & \\
* Previously published in Ref. [13]. & &
\end{tabular}

Calculation of the incidence of venous anomalies detected by MR cannot be made from our data, since the MR studies were performed on patients in specific research protocols rather than on the general population. Furthermore, practical constraints prevented using all pulse sequences in all patients. It is possible that additional anomalies might have been detected had wider ranges of pulse sequences been employed for all patients examined.

\section{DISCUSSION}

The normal SVC develops embryologically from the paired anterior cardinal veins. These join the paired posterior cardinal veins to form the ducts of Cuvier which empty into the sinus venosus. When the left brachiocephalic vein forms, it connects the left anterior cardinal vein to its right sided counterpart. As the caudal left anterior cardinal vein, the left duct of Cuvier, and the left side of the sinus venosus regress (remaining as the oblique vein of Marshall and the coronary sinus), the left brachiocephalic vein drains the left subclavian and jugular veins into the right anterior cardinal vein, now recognized as the SVC. If the left brachiocephalic vein fails to form, and the left anterior cardinal does not regress, then a left SVC persists in addition to the right SVC. Similarly if the right anterior cardinal vein regresses, the left SVC persists alone $[1,11,14]$. 


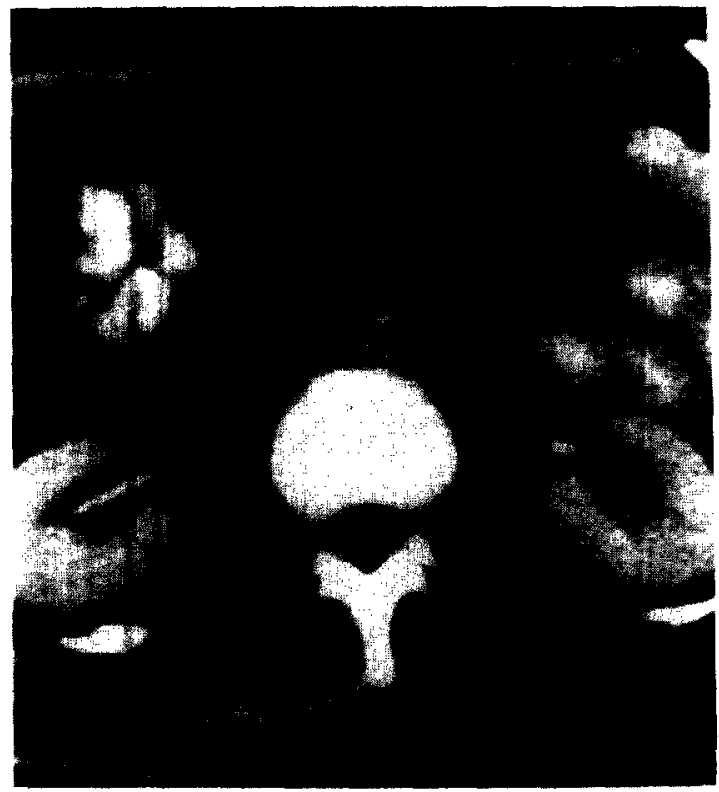

(a)

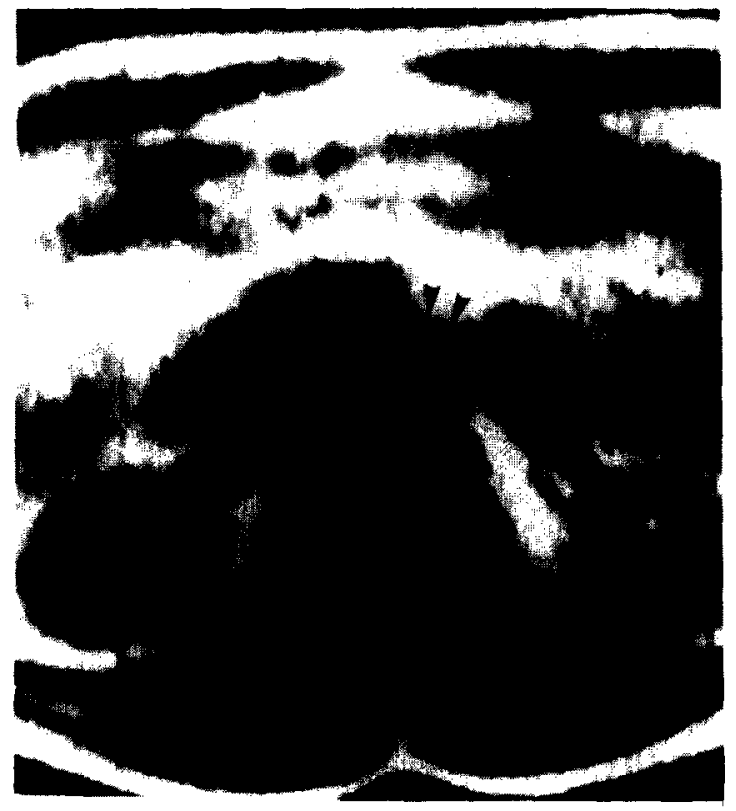

(c)

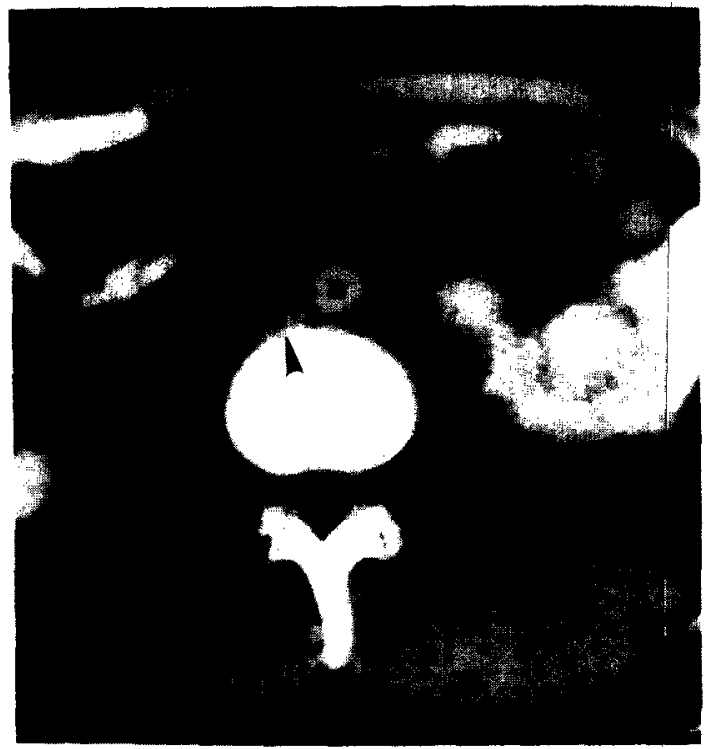

(b)

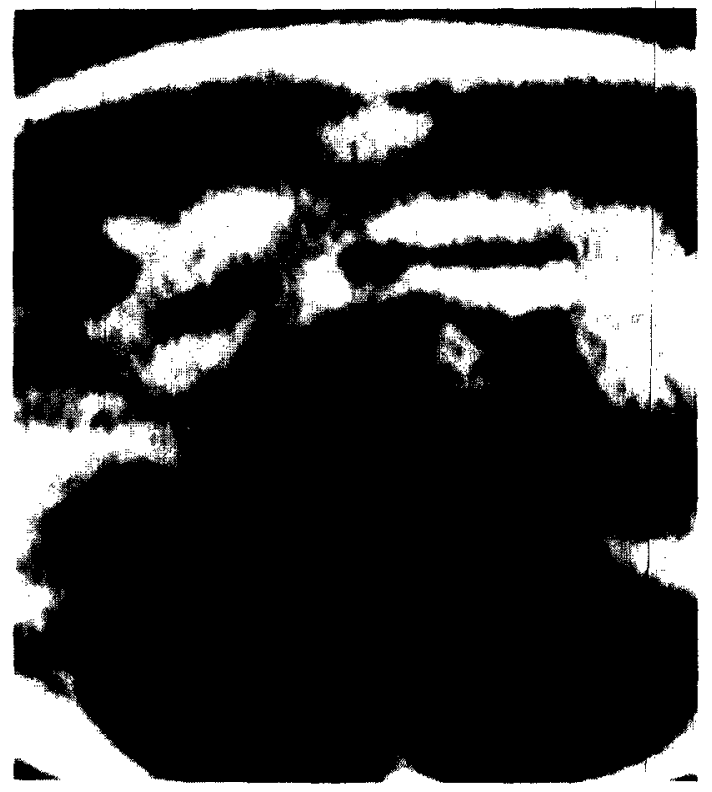

(d)

Fig. 1. (a) Case 2. A 33-year-old male with testicular cancer. CT image at the level of the renal hila shows preaortic LRV (arrowheads) crossing in front of the aorta. (b) CT image at the level of the inferior poles of the kidneys shows the retroaortic LRV as it enters the IVC (arrowhead). (c) MR SE 30/500 (echo time/repetition time) image at level similar to (a). Arrowheads indicate the preaortic LRV. (d) MR SE 30/500 image at level similar to (b). It is difficult to separate the retroaortic LRV $\left({ }^{*}\right)$ from the cortical bone of the vertebral body. a-aorta; c-inferior vena cava.

Most commonly the anomalous left SVC empties into the coronary sinus; many of these cases are asymptomatic, but there is an increased incidence of cardiac anomalies. The left SVC may drain into the left atrium, resulting in a shunt. In this situation, associated cardiac abnormalities are frequent. with atrial septal defect the most common [11].

The inferior vena cava and renal venous system develops embryologically from three paired venous structures: the posterior cardinal veins, the subcardinal veins and the supracardinal veins $[6,8,9,15-17]$. The posterior cardinal veins are the earliest system to form, appearing at approx. 6 


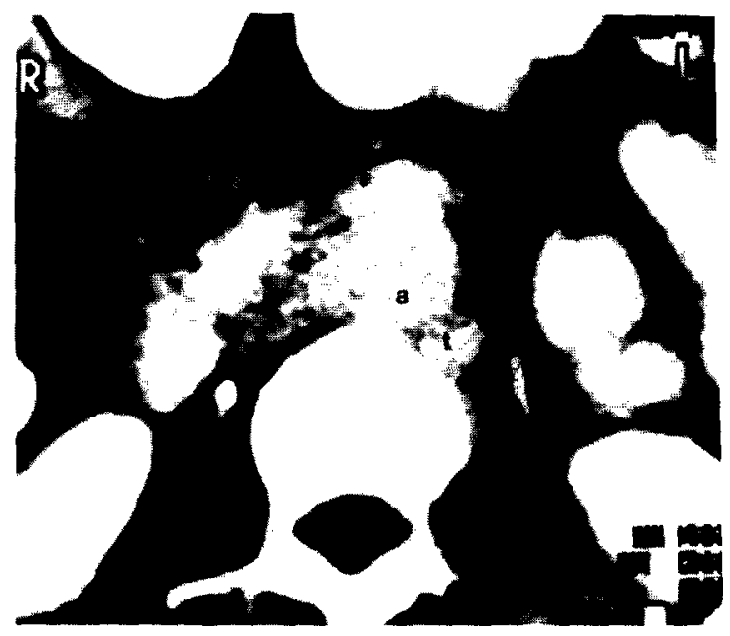

(a)

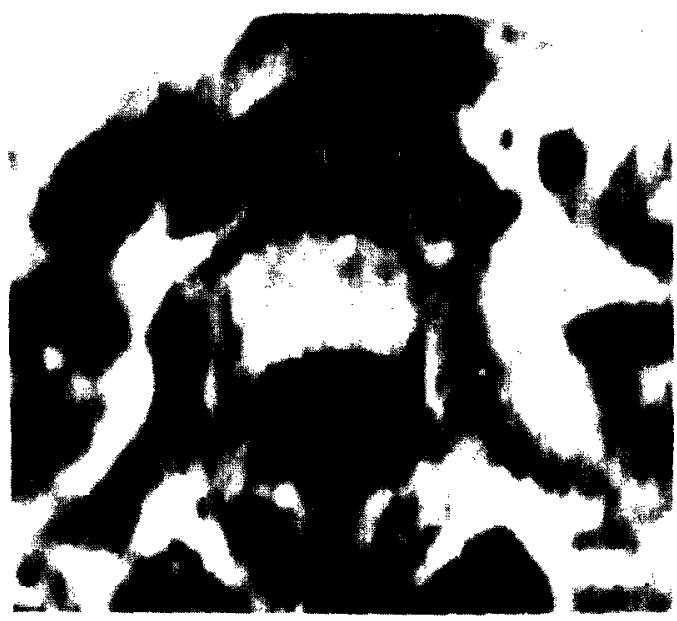

(b)

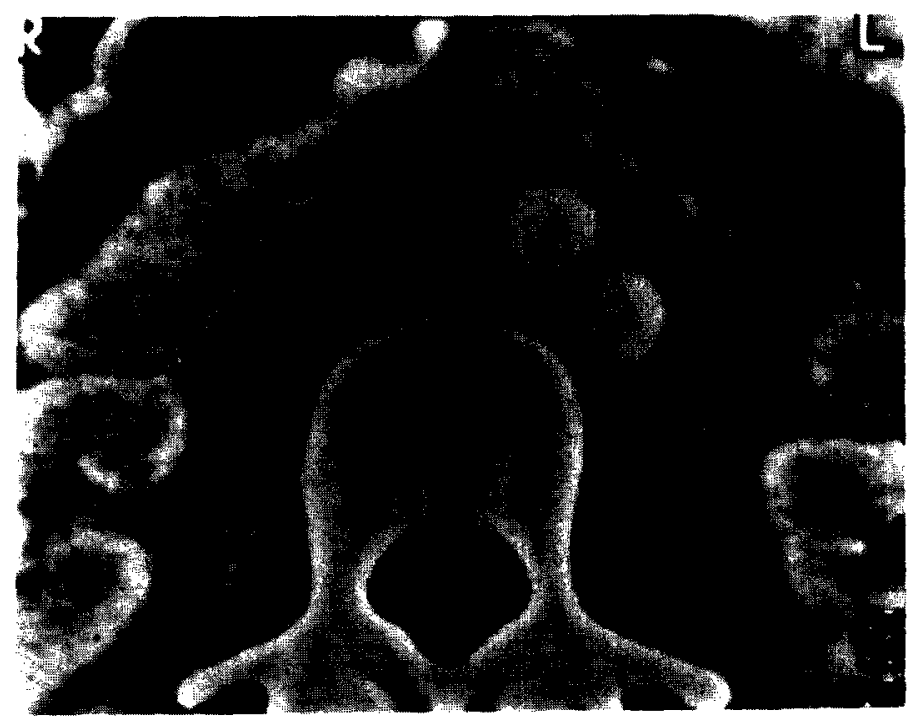

(c)

Fig. 2. (a) Case 4. A 56-year-old female with ovarian cancer. CT section at the lower pole of the kidney with drip infusion of intraveneous contrast. The aorta appears aneurysmal, and there is soft tissue (t) to the left of the aorta that suggests adenopathy. (b) MR SE 24/250 image at level similar to (a), showing the vascular nature of the left paraaortic structure (r), which is the vertical portion of a retroaortic LRV. The aorta is normal, but there is an interaortocaval soft tissue mass $(\mathrm{m})$. (c) CT section performed with bolus contrast injection. The aorta is normal, but surrounded by mass $(\mathrm{m})$, representing adenopathy (metastasis confirmed by needle biopsy). The vascular structure ( $r$ ) to the left of the aorta is a retroaortic LRV that parallels the aorta over several slices before crossing the midline to join the IVC. a-aorta: $c$-inferior vena cava.

weeks of development. They later regress, making no contribution to the adult IVC. They do persist as the iliac bifurcation.

The subcardinal veins develop medial and ventral to the posterior system, appearing at 7 weeks. They form anastomoses with the posterior cardinal system, between themselves, and with the hepatic vessels. The portion of the right subcardinal vein connecting with the hepatic veins persists in the adult as the prerenal IVC. The remainder of the subcardinal system regresses.

At 8 weeks the supracardinal system develops dorsal and medial to the regressing posterior system, extending above the diaphragm. The caudal portion of the left supracardinal vein normally regresses. The right persists as the postrenal IVC and receives the drainage from the posterior cardinals forming the iliac bifurcation. The suprarenal portions of both supracardinal veins persist as the azygos and hemiazygos systems. 


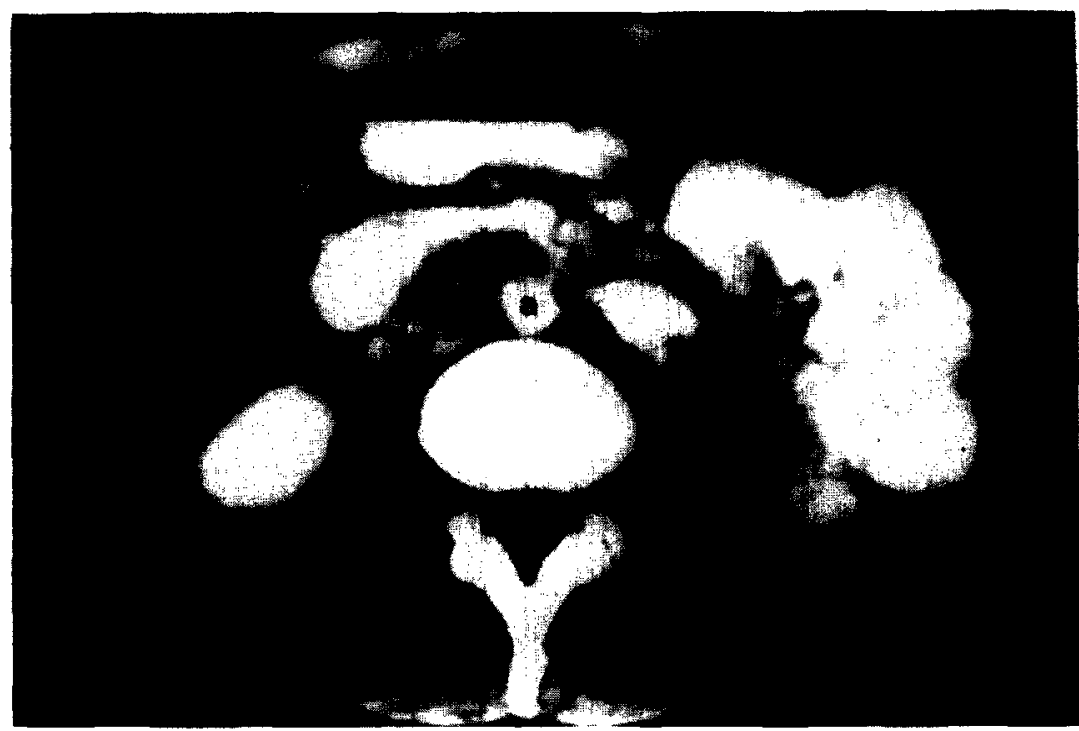

(a)

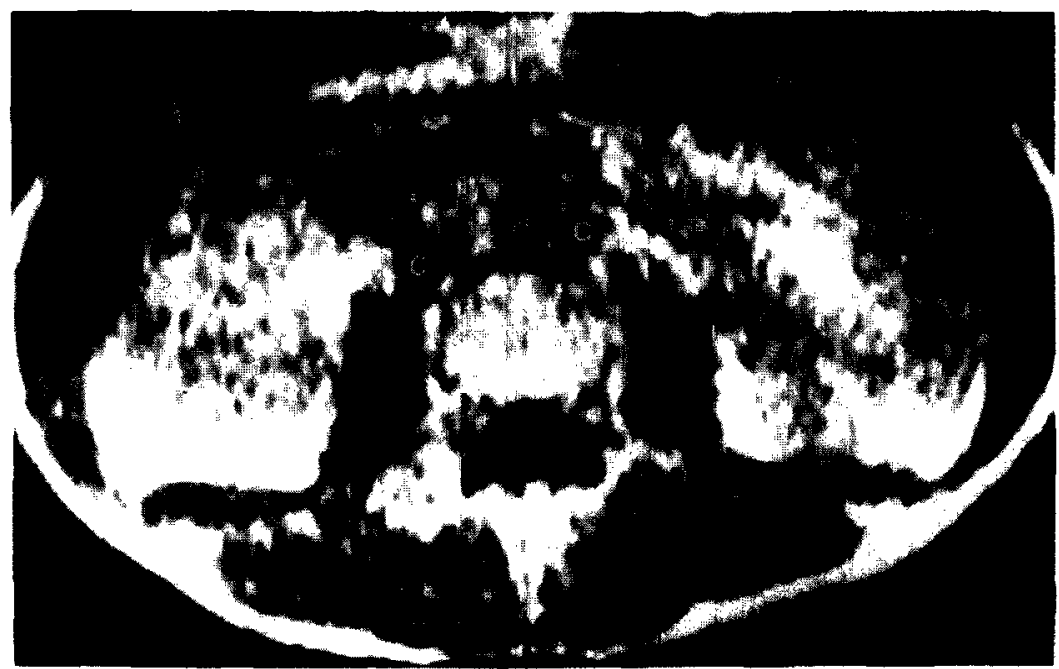

(b)

Fig. 3. (a) Case 6. A 46-year-old male with testicular cancer. CT section at the level of the inferior pole of the kidney. There are two equally enhancing structures (c) of similar size, representing duplication of the IVC. Interaortocaval adenopathy ( $t$ ) is also identified. (b) MR SE 30/500 image at level similar to (a). Both cavae (c) are seen. but the left sided vessel has higher signal than aorta or right cava. Metastatic tumor (t) not well shown using this pulse sequence. a-aorta.

Inter-supracardinal and supracardinal-subcardinal anastomoses form a ring (renal collar) around the aorta with dorsal and ventral components to each kidney. Normally the retroaortic segment of the ring regresses. The preaortic portion remains, contributing to the left renal vein.

A variety of congenital anomalies result if venous segments fail to regress in the normal fashion. The most common of these are described in Table 3.

As shown in Table 1, CT demonstrates transposition of the IVC with a frequency comparable to that of autopsy series [6-8]. Duplication of the IVC is found less frequently by CT than by autopsy. This has been explained by noting that the vessel caliber of the duplication may be below the resolution of the scanner used [7]. CT also finds fewer cases of circumaortic LRV than does autopsy. The retroaortic component may be small, difficult to resolve by CT, but not missed by careful dissection. Surgical frequency is also lower than autopsy frequency and explained by Brener [17] as small venous networks that are surgically insignificant retroaortic contributions. 


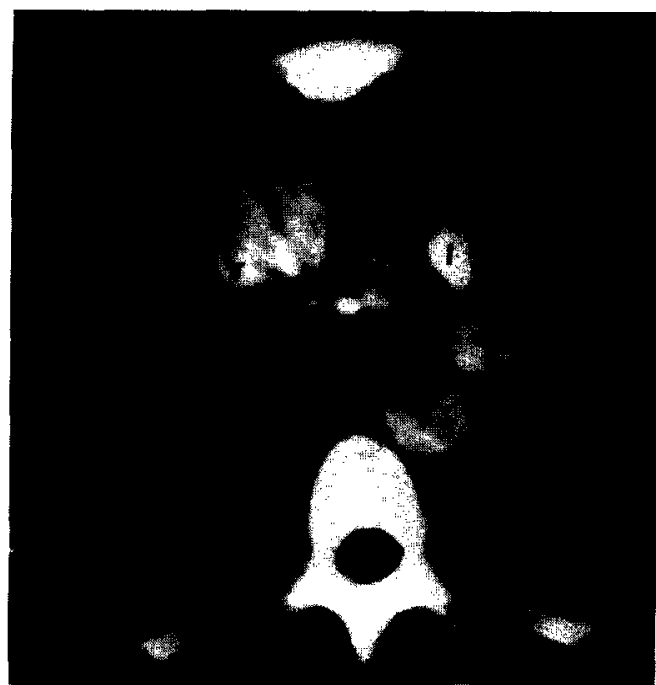

(a)

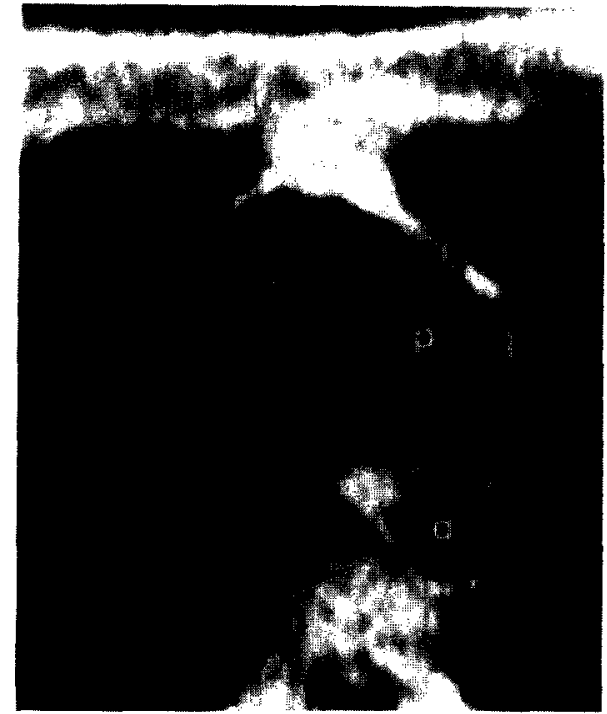

(b)

Fig. 4. (a) Case 7. A 58-year-old white male with testicular cancer. CT section at the level of the left pulmonary artery with drip infusion of contrast through a left arm vein. The left SVC (1) is filled with contrast. The right SVC (r) is less obvious due to less enhancement. Both cavae are similar in size. (Courtesy of John C. Spellmeyer, M.D., Richmond, Ind.) (b) MR 30/1000 image at level similar to (a). There is poor visualization of both left (1) and right (r) SVC components because surrounding lung has similar signal. There is little mediastinal fat to help separate the mediastinal vessels. a-ascending dorta; $d$-descending aorta; $p$ - left pulmonary artery.

The increased contrast resolution afforded most vascular structures when imaged using MR results from the flow void phenomenon [12]. The rapidly flowing blood in vessels emits low signal and thus can be easily differentiated from surrounding soft tissue. Variation in the radiofrequency pulse sequence, method of slice acquisition, intraluminal turbulence and flow rate all have an effect on the emitted signal.

Contrast resolution of vessels by $\mathrm{CT}$ requires adequate delivery of contrast and often the use of bolus technique. Adequate fat around the vessels aids in separating them from surrounding enhancing structures. Soft tissue enhancement to a similar degree as vascular structures may make it difficult to distinguish vessels from adenopathy [16, 18]. Case 4 (Fig. 2) demonstrates these problems. With a drip infusion, a retroaortic left renal vein could not be distinguished from adenopathy, since its enhancement was similar to soft tissue and less than the aorta. Only after a bolus of contrast was it clearly identified as a vessel. The low signal from this structure on MR made its vascular nature obvious.

Demonstration of a retroaortic left renal vein on MR can be difficult. As it crosses in front of the vertebral body, the low signal from cortical bone blends with the low signal from the vessel. Interposed

Table 3. Embryologic origin of inferior vena caval anomalies

\begin{tabular}{ll}
\hline Duplication of IVC & $\begin{array}{l}\text { Persistent left supracardinal vein; usually crossover to } \\
\text { prerenal IVC via LRV }\end{array}$ \\
Transposition of IVC & $\begin{array}{l}\text { Regression of right supracardinal vein with persistence } \\
\text { of postrenal segment of left supracardinal vein }\end{array}$ \\
Retroatrtic LRV & $\begin{array}{l}\text { Regression of anterior anastomosis of renal collar, with } \\
\text { persistence of posterior connection }\end{array}$ \\
Circumaortic LRV & $\begin{array}{l}\text { Persistence of anterior and posterior anastomoses of } \\
\text { renal collar }\end{array}$ \\
Retrocaval ureter & $\begin{array}{l}\text { Persistence of right posterior cardinal vein or sub- } \\
\text { cardinal vein with atrophy of the right supracardinal } \\
\text { vein; almost invariably right sided }\end{array}$ \\
Azygos continuation & Failure of right subcardinal and hepatic vein to fuse \\
\hline
\end{tabular}

LRV-left renal vein; IVC-inferior vena cava. 
fat or identification of the anomalous vein at another level may help. With CT, confusion between a soft-tissue density vein and cortical bone is unlikely, although it could be mistaken for adenopathy. Similarly, MR failed to clearly demonstrate a duplicated SVC (Fig. 4). Since the lung also has very low signal, it is difficult to separate flowing blood from lung. Adequate mediastinal fat is necessary to delineate vessels adjacent to lung parenchyma. Anomalous vessels in the chest are easily visualized by $\mathrm{CT}$, since their attenuation is markedly different from lung. CT may have more difficulty in distinguishing them from soft tissue masses. The characteristic appearance over several slices and the use of bolus techniques aid in the CT recognition of an anomalous vein [19].

Slow flowing blood can emit some MR signal. Different regions of the vascular network have varying signal intensity depending on the flow rate in that segment [20]. This signal emission can make it more difficult to distinguish a vessel from soft tissue. The duplicated IVC (Fig. 3) showed higher signal intensity from the anomalous left component than from the other great vessels, making its identification difficult on MR. Often the left component will be much smaller than the right. In this example, both components are of equal size, well within the resolution of either cross-sectional modality.

\section{SUMMARY}

MR is capable of demonstrating congenital anomalies of the systemic veins. As MR utilization expands, radiologists must be aware of the appearance of these incidental anomalies. The MR contrast resolution between vascular structures with rapidly flowing blood and soft tissues is superior to that of $\mathrm{CT}$, due to the flow void phenomenon. However, MR has difficulty when structures adjacent to vessels also have low signal. Vessels adjacent to cortical bone or lung may go unrecognized unless the thin vascular wall can be resolved.

\section{REFERENCES}

1. E. M. Cha and G. H. Khoury, Persistent left superior vena cava, Radiology 103, 375381 (1972).

2. G. A. Seib, The azygous system of veins in American White and American Negroes, including observations of the inferior caval venous systems, Am. J. Phys. Anthropol. 19, 39-163 (1934).

3. B. Adachi, Statistik der Varietaten der V. cava Caudalis bei den Japanern, Anat. Anz. 85, 215-223 (1937).

4. R. H. Reis and G. Esenther, Variations in the pattern of renal vessels and their relation to the type of posterior vena cava in man, Am. J. Anat. 104, 295-318 (1959).

5. C. J. Davis and G. D. Lundberg, Retroaortic left renal vein: a relatively frequent anomaly, Am. J. clin. Path. 50, 700-703 (1968).

6. E. S. Alexander, R. A. Clark, B. H. Gross and D. P. Colley, CT of congenital anomalies of the inferior vena cava. Computerized Radiol. 6, 219-226 (1982).

7. J. Ueda, K. Hara, Y. Kobayashi, S. Ohue and H. Uchida, Anomaly of the inferior vena cava observed by CT, Computerized Radiol. 7, 145-154 (1983).

8. J. Mayo, R. Gray, E. St. Louis, H. Grosman, M. McLoughlin and D. Wise, Anomalies of the inferior vena cava, Am. J. Roentg. 140, 339-345 (1983).

9. R. J. Babaian and D. E. Johnson, Major venous anomalies complicating retroperitoneal surgery, Sth. med. J. 72, 1254 .1258 (1979).

10. S. A. Royal and P. W. Callen, CT evaluation of anomalies of the inferior vena cava and left renal vein. Am. J. Roentg. 132, 759-763 (1979).

11. H. B. Shumacker Jr, H. King and J. A. Waldhausen, The persistent left superior vena cava, Surgical implications, with special reference to caval drainage into the left atrium, Ann. Surg. 165, 797-805 (1967).

12. C. M. Mills, M. Brant-Zawadzki, L. E. Crooks, L. Kaufman, P. Sheldon, D. Norman, W. Bank and T. H. Newton, Nuclear magnetic resonance: principles of blood flow imaging, Am. J. Roentg. 142, 165-170 (1984).

13. D. A. Cory, J. H. Ellis, J. R. Bies and E. W. Olson, Retroaortic left renal vein demonstrated by nuclear magnetic resonance imaging, J. Comput. assist. Tomogr 8, 339340 (1984).

14. M. A. Bettman, The superior vena cava, In Abrams Angiography: Vascular and Interventional Radiology, Abrams H. L., Ed., 3rd edn, pp. 923-938. Little Brown, Boston, Mass. (1983).

15. E. J. Ferris, The inferior vena cava, In Abrams Angiography: Vascular and Interventional Radiology, Abrams H. L., Ed., 3rd edn, pp. 939-975. Little Brown, Boston, Mass. (1983).

16. S. 1. Cohen, P. Hochsztein, J. Cambio and J. Susset, Duplicated inferior vena cava misinterpreted by computerized tomography as metastatic retroperitoneal testicular tumor, J. Urol. 128, 389-391 (1982).

17. B. J. Brener, R. C. Darling, P. L. Frederick and R. R. Linton, Major venous anomalies complicating abdominal aortic surgery, Archs Surg 108, 159-165 (1974).

18. R. L. Baron, F. R. Gutierrez, S. S. Sagel, R. G. Levitt and R. C. McKnight, CT of anomalies of the mediastinal vessels. Am. J. Roentg. 137, 571-576 (1981).

19. T. J. Huggins, M. L. Lesar, A. C. Friedman, R. S. Pyatt, and T. T. Thane, CT appearance of persistent left superior vena cava, J. Comput. assist. Tomogr. 6, 294-297 (1982).

20. C. B. Higgins, H. Goldberg. H. Hricak, L. E. Crooks, L. Kaufman and R. Brasch, Nuclear magnetic resonance imaging of vasculature of abdominal viscera: normal and pathologic features, Am. J. Roentg. 140, 1217-1225 (1983). 
About the Author-James H. Ellis, M.D. graduated from the University of Michigan Medical School. Following residency in diagnostic radiology at Indiana University Medical Center, he joined the staff of Indiana University Hospital. He is currently Assistant Professor of Radiology at the University of Michigan Medical Center, and Chief of the Radiology Service at the Ann Arbor Veterans Administration Medical Center.

About the Author-Janette S. Denham, M.D. received a B.S. degree in biology from Purdue University in 1979. In 1983, she was awarded the M.D. degree from the Indiana University School of Medicine. Dr Denham is currently a resident in diagnostic radiology at the Indiana University Medical Center.

About the Author-JOHN R. Bies, M.D. graduated from Indiana University School of Medicine in 1979 and had his residency training in diagnostic radiology at the same institution, where he also served as a lecturer and then Assistant Professor of Radiology from May 1983 to June 1984. Dr Bies now practices at St. Mary's Medical Center in Evansville, Indiana. Dr Bies is a Diplomate of The American Board of Radiology and is also a member of the American Medical Association, The American College of Radiology, The Radiological Society of North America, and The American Institute of Ultrasound in Medicine.

About the Author-ELDON W. Olson, M.D. received a B.S. degree in biology from the University of Illinois in 1975, and the M.D. degree from the same institution in 1979. His diagnostic radiology residency training was at Indiana University Medical Center in Indianapolis, with board certification in Diagnostic Radiology in 1983. Dr Olson completed a fellowship in CT-ultrasound and chest radiology at Indiana University. He then remained at the institution for 2 years as an Assistant Professor, specializing in interventional radiology. $\mathrm{He}$ is now in private practice in Lexington, Kentucky.

About the Author-DAvid A. CoRy, M.D. graduated from the University of Evansville summa cum laude with a B.S. degree in biology in 1977. He graduated from the Indiana University School of Medicine in 1981. From 1981 to 1985 . Dr Cory was a resident in diagnostic radiology at the Indiana University Medical Center, spending his fourth year of residency in a Junior Staff capacity at James Whitcomb Riley Hospital for Children. He is a diplomate of the American Board of Radiology. Dr Cory is presently an Assistant Professor of Radiology at Riley Hospital. 